\title{
Natural Fiber Reinforced Polymer Composites for Automobile Accessories
}

\author{
Chandramohan, D. and J. Bharanichandar \\ Department of Mechanical Engineering, Vel Tech. (Owned By R S Trust), Avadi, Chennai, Tamilnadu, India
}

Received 2013-11-27; Revised 2013-12-04; Accepted 2014-01-17

\begin{abstract}
The invention is an effort to utilize the advantages offered by renewable resources for the development of composite materials based on polymer and particles of natural fibers for Conservation of natural resources. In this research, natural fibers like Sisal (Agave sisalana), Banana (Musa sepientum) and Roselle (Hibiscus sabdariffa), Sisal and banana (hybrid), Roselle and banana (hybrid) and Roselle and sisal (hybrid) are fabricated with bio epoxy resin using molding method. The applications of these materials require a sustainable approach to creating green products. Green materials are very important to form environment friendly from renewable resources and decrease the use of petroleum based chemicals. Nowadays natural fibers form an interesting alternative for the most widely applied fibre in the composite technology, glass. The use of fibers like sisal, Roselle and banana in this industry so far is small since availability of a durable semifinished product with constant quality is often a problem. Recent research and development have shown that these aspects can be improved considerably. Knowing that natural fibers are cheap and have a better stiffness per weight than glass, which results in lighter components, the grown interest in natural fibers is clear. Secondly, the environmental impact is smaller since the natural fibre can be thermally recycled and fibers come from a renewable resource. Their moderate mechanical properties restrain the fibers from using them in high-tech applications, but for many reasons they can compete with glass fibers. In this paper the optimum mixing of fiber and resin is achieved by using Taguchi method. In this work, tensile and hardness of Sisal and banana (hybrid), Roselle and banana (hybrid and Roselle and sisal (hybrid) composite at dry and wet conditions were studied. Hardness test were conducted using Brinell hardness testing machine. In this work micro structure of the specimens are scanned by the Scanning Electron Microscope. The disclosure includes the process to make the composite and also the variety of products in automobile accessories.
\end{abstract}

Keywords: Natural Fibers, Bio Epoxy Resin, Tensile Test, Hardness Test, Taguchi Method, SE, Automobile Accessories

\section{INTRODUCTION}

Nowadays, the natural fibers such as Sisal, Banana and Roselle have the potential to be used as a replacement for glass or other traditional reinforcement materials in composites (Abrao et al., 2006) Other advantages include low density, high toughness, comparable specific strength properties, reduction in tool wear, ease of separation, decreased energy of fabrication. Composites are materials that comprise strong load carrying material (known as re-inforcement) imbedded in weaker material (known as matrix). Reinforcement provides strength and rigidity, helping to support structural load (Boeree et al., 1993). The matrix, or binder (organic or in-organic) maintains the position and orientation of the reinforcement (Joseph et al., 1999). They have high specific properties such as stiffness, impact resistance, flexibility and modulus. In addition, they are available in large amounts and are renewable and biodegradable. Other desirable properties include low cost, low density. Uses of these fibers satisfy both economic and ecological interests (Blazewicz et al., 1997). The results showed that the highest mechanical properties were observed when Roselle and sisal (hybrid) Chennai, Tamilnadu, India 
fibers were incorporated. It is well understood now that both the strength and stiffness of fiber composites depend on fiber concentration, fiber aspect ratios, fibermatrix adhesion, as well as powdered particles of fiber orientation and dispersion. The present contribution reports utilization of untreated Sisal, Banana and Roselle fibers as reinforcing fillers for bio epoxy resin Grade 3554A and Hardener 3554B as matrix for the first time (Chandramohan and Marimuthu, 2010a). The Roselle and sisal (hybrid) Sisal and banana (hybrid) and Roselle and banana (hybrid) fiber-reinforced polymer composites were prepared using hand molding method. The effects of fibers content on mechanical properties such as, tensile and hardness of the composites were investigated and reported.

\section{MATERIALS AND METHODS}

- The matrix material used in this investigation was bio epoxy resin Grade 3554A and Hardner 3554B. Supplied by Lab chemicals, Chennai

- Roselle, banana and sisal fibers have been used traditionally in high strength ropes in India especially in South India regions (Chandramohan et al., 2010a)

\subsection{Manufacturing Process}

\subsubsection{Chemical Treatment}

The fibers are powdered. Then the fibers are cleaned normally in clean running water and dried. A glass beaker is taken and $6 \% \mathrm{NaOH}$ is added and $80 \%$ of distilled water is added and a solution is made. After adequate drying of the fibers in normal shading for 2 to 3 $\mathrm{h}$, the fibers are taken and soaked in the prepared $\mathrm{NaOH}$ solution. Soaking is carried out for different time intervals depending upon the strength of fiber required. In this study, the fibers are soaked in the solution for three hours. After the fibers are taken out and washed in running water, these are dried for another $2 \mathrm{~h}$. The fibers are then taken for the next fabrication process namely the Procasting process (Chandramohan et al., 2010b).

\subsection{Moisture Absorption Test Procedure}

Flexural specimens as per ASTM standards were cut from the fabricated plate. Edges of the samples were sealed with polyester resin and subjected to moisture absorption. The composite specimens to be used for moisture absorption test were first dried in an air oven at $50^{\circ} \mathrm{C}$. Then these conditioned composite specimens were immersed in distilled water at $30^{\circ} \mathrm{C}$ for about 5 days
(Clemons and Caulfield, 1994). At regular intervals, the specimens were removed from water and wiped with filter paper to remove surface water and weighed with digital balance of $0.01 \mathrm{mg}$ resolution. The samples were immersed in water to permit the continuation of sorption until saturation limit was reached. The weighing was done within $30 \mathrm{~s}$, in order to avoid the error due to evaporation. The test was carried out according to ASTM D570 to find out the swelling of specimen. After 5 days, the test specimens were again taken out of the water bath and weighed (Chandramohan and Marimuthu, 1994; 2000; 2010b).

\subsection{Tensile Test}

The tensile strength of the composites (with and without moisture) was measured with a universal testing machine in accordance with the ASTM D638 procedure.

\subsection{Taguchi Quality Loss Function}

A different method of measuring quality is central to Taguchi's approach to design. Loss function measures quality. The loss function establishes a financial measure of the user dissatisfaction with the products performance as it deviates from the target value. Thus, both average performance and variation are critical measures of quality. Selecting a product design or a manufacturing process that is insensitive to uncontrolled sources of variation improves quality.

\subsection{Orthogonal Array of Experiments}

By evaluating the performance of the product in several environmental conditions, there would be a realistic data to calculate the real world variance. The classical experimental design method are too complex, time consuming and not easy to use. A large number of experiments have to be carried out when the number of process parameters are more. To solve this problem, taguchi method uses a special design of orthogonal arrays to study the entire parameter space with the minimum number of experiments.

\subsection{Sisal and Roselle (Tensile test)}

A natural fibers hybrid polymer composite material is fabricated using moulding method In this calculation the following six factors are identified, each two levels. Here only main effects are considered.

Total DOF $=6(6 \mathrm{X}(2-1))$, So $\mathrm{L}_{8} \mathrm{OA}$ was selected for calculation. The 6-factors are assigned to the first 6columns (Table 1-7). The response variable $(\mathrm{Y})$ is youngs modulus in $\mathrm{N} / \mathrm{mm}^{2}$. Only one repetition was performed. 
Table 1. Sisal and roselle (with moisture)

\begin{tabular}{lllllll}
\hline Load & Deformation & & & & & \\
$\mathrm{N}$ & ------------------- & & & \\
\hline 98.1 & $\mathrm{~A}$ & $\mathrm{~B}$ & $\Delta \mathrm{L} \mathrm{Avg},(\mathrm{A}+\mathrm{B}) / 2$ & $\sigma\left(\mathrm{N} / \mathrm{mm}^{2}\right)$ & $\varepsilon$ & $\mathrm{E}\left(\mathrm{N} / \mathrm{mm}^{2}\right)$ \\
196.2 & 0.0014 & 0.0021 & 0.00175 & 0.3122712 & $1.75 \mathrm{E}-05$ & 17844.0690 \\
294.3 & 0.0025 & 0.0048 & 0.00365 & 0.6245424 & $3.65 \mathrm{E}-05$ & 17110.7511 \\
392.4 & 0.0040 & 0.0069 & 0.00545 & 0.9368136 & $5.45 \mathrm{E}-05$ & 17189.2408 \\
490.5 & 0.0053 & 0.0082 & 0.00675 & 1.2490848 & $6.75 \mathrm{E}-05$ & 18504.9605 \\
588.6 & 0.0065 & 0.0108 & 0.00865 & 1.5613560 & $8.65 \mathrm{E}-05$ & 18050.3588 \\
686.7 & 0.0078 & 0.0128 & 0.01030 & 1.8736272 & 0.000103 & 18190.5568 \\
784.8 & 0.0091 & 0.0149 & 0.01200 & 2.1858985 & 0.000120 & 18215.8205 \\
882.9 & 0.0104 & 0.0169 & 0.01365 & 2.4981697 & 0.000137 & 18301.6093 \\
981 & 0.0117 & 0.0184 & 0.01505 & 2.8104409 & 0.000151 & 18674.0257 \\
1079.1 & 0.0140 & 0.0210 & 0.01750 & 3.1227121 & 0.000175 & 17844.0690 \\
1177.2 & 0.0143 & 0.0235 & 0.01890 & 3.4349833 & 0.000189 & 18174.5148 \\
1275.3 & 0.0156 & 0.0259 & 0.02075 & 3.7472545 & 0.000208 & 18059.0578 \\
1373.4 & 0.0169 & 0.0271 & 0.02200 & 4.0595257 & 0.000220 & 18452.3896 \\
1471.5 & 0.0182 & 0.0291 & 0.02365 & 4.3717969 & 0.000237 & 18485.3990 \\
1569.6 & 0.0196 & 0.0312 & 0.02540 & 4.6840681 & 0.000254 & 18441.2131 \\
1667.7 & 0.0208 & 0.0332 & 0.02700 & 4.9963393 & 0.000270 & 18504.9605 \\
1765.8 & 0.0223 & 0.0359 & 0.02910 & 5.3086105 & 0.000291 & 18242.6479 \\
1863.9 & 0.0234 & 0.0372 & 0.03030 & 5.6208817 & 0.000303 & 18550.7648 \\
1962 & 0.0247 & 0.0393 & 0.03200 & 5.9331530 & 0.000320 & 18541.1030 \\
2060.1 & 0.0260 & 0.0450 & 0.03550 & 6.2454242 & 0.000355 & 17592.7441 \\
2158.2 & 0.0273 & 0.0446 & 0.03595 & 6.5576954 & 0.000360 & 18241.1554 \\
2256.3 & 0.0286 & 0.0459 & 0.03725 & 6.8699666 & 0.000373 & 18442.8633 \\
2354.4 & 0.0299 & 0.0480 & 0.03895 & 7.1822378 & 0.000390 & 18439.6349 \\
2452.5 & 0.0312 & 0.0511 & 0.04115 & 7.4945090 & 0.000412 & 18212.6585 \\
\hline & 0.0328 & 0.0517 & 0.04225 & 7.8067802 & 0.000423 & 18477.5863 \\
\hline
\end{tabular}

Table 2. Sisal and roselle (without moisture)

\begin{tabular}{lccllllll}
\hline \multicolumn{7}{c}{ Load } & & \multicolumn{2}{l}{ Deformation } & & & & \\
S. No & kg & N & A & B & $\Delta$ L Avg $(\mathrm{A}+\mathrm{B}) / 2$ & $\sigma\left(\mathrm{N} / \mathrm{mm}^{2}\right)$ & $\varepsilon$ & $\mathrm{E}\left(\mathrm{N} / \mathrm{mm}^{2}\right)$ \\
\hline 1 & 10 & 98.1 & 0.0013 & 0.0021 & 0.00170 & 0.31227121 & $1.7 \mathrm{E}-05$ & 18368.89459 \\
2 & 20 & 196.2 & 0.0026 & 0.0048 & 0.00370 & 0.62454242 & $3.7 \mathrm{E}-05$ & 16879.52476 \\
3 & 30 & 294.3 & 0.0039 & 0.0069 & 0.00540 & 0.93681362 & $5.4 \mathrm{E}-05$ & 17348.40045 \\
4 & 40 & 392.4 & 0.0052 & 0.0082 & 0.00670 & 1.24908483 & $6.7 \mathrm{E}-05$ & 18643.05720 \\
5 & 50 & 490.5 & 0.0065 & 0.0107 & 0.00860 & 1.56135604 & $8.6 \mathrm{E}-05$ & 18155.30279 \\
6 & 60 & 588.6 & 0.0078 & 0.0128 & 0.01030 & 1.87362725 & 0.00010 & 18190.55581 \\
7 & 70 & 686.7 & 0.0091 & 0.0148 & 0.01195 & 2.18589846 & 0.00012 & 18292.03729 \\
8 & 80 & 784.8 & 0.0104 & 0.0169 & 0.01365 & 2.49816966 & 0.00014 & 18301.60926 \\
9 & 90 & 882.9 & 0.0117 & 0.0184 & 0.01505 & 2.81044087 & 0.00015 & 18674.02573 \\
10 & 100 & 981.0 & 0.0130 & 0.0210 & 0.01700 & 3.12271208 & 0.00017 & 18368.89459 \\
11 & 110 & 1079.0 & 0.0143 & 0.0235 & 0.01890 & 3.43498329 & 0.00019 & 18174.51475 \\
12 & 120 & 1177.0 & 0.0156 & 0.0258 & 0.02070 & 3.74725450 & 0.00021 & 18102.67873 \\
13 & 130 & 1275.0 & 0.0169 & 0.0271 & 0.02200 & 4.05952570 & 0.00022 & 18452.38956 \\
14 & 140 & 1373.0 & 0.0182 & 0.0291 & 0.02365 & 4.37179691 & 0.00024 & 18485.39921 \\
15 & 150 & 1472.0 & 0.0195 & 0.0311 & 0.02530 & 4.68406812 & 0.00025 & 18514.10324 \\
16 & 160 & 1570.0 & 0.0208 & 0.0332 & 0.02700 & 4.99633933 & 0.00027 & 18504.96048 \\
17 & 170 & 1668.0 & 0.0221 & 0.0359 & 0.02900 & 5.30861054 & 0.00029 & 18305.55357 \\
18 & 180 & 1766.0 & 0.0234 & 0.0372 & 0.03030 & 5.62088174 & 0.00030 & 18550.76483 \\
19 & 190 & 1864.0 & 0.0247 & 0.0393 & 0.03200 & 5.93315295 & 0.00032 & 18541.10298 \\
20 & 200 & 1962.0 & 0.0260 & 0.0430 & 0.03450 & 6.24542416 & 0.00035 & 18102.67873 \\
21 & 210 & 2060.0 & 0.0273 & 0.0446 & 0.03595 & 6.55769537 & 0.00036 & 18241.15541 \\
22 & 220 & 2158.0 & 0.0286 & 0.0459 & 0.03725 & 6.86996658 & 0.00037 & 18442.86329 \\
23 & 230 & 2256.0 & 0.0299 & 0.0479 & 0.03890 & 7.18223778 & 0.00039 & 18463.33621 \\
24 & 240 & 2354.0 & 0.0312 & 0.0511 & 0.04115 & 7.49450899 & 0.00041 & 18212.65855 \\
25 & 250 & 2453.0 & 0.0325 & 0.0515 & 0.04200 & 7.80678020 & 0.00042 & 18587.57191 \\
\hline & & & & & & & &
\end{tabular}


Table 3. Factors and levels

\begin{tabular}{llll}
\hline No. of factors & Factors & Level I & Level II \\
\hline A & R.F (gms) & 85 & 90 \\
B & S.F (gms) & 85 & 90 \\
C & Epoxy (gms) & 50 & 55 \\
D & A. Ratio of R.F & 10 & 15 \\
E & A. Ratio of S.F & 10 & 15 \\
F & A. T & Yes & No \\
\hline
\end{tabular}

Table 4. Factors and levels

\begin{tabular}{|c|c|c|c|c|c|c|c|}
\hline \multirow{4}{*}{$\begin{array}{l}\text { No of } \\
\text { experiments } \\
\text { (Trial) }\end{array}$} & \multicolumn{6}{|c|}{ Factors } & \multirow[b]{4}{*}{$\operatorname{In}\left(\mathrm{KN} / \mathrm{mm}^{2}\right)$} \\
\hline & A & B & $\mathrm{C}$ & $\mathrm{D}$ & $\mathrm{E}$ & $\mathrm{F}$ & \\
\hline & 1 & 2 & 3 & 4 & 5 & 6 & \\
\hline & $\begin{array}{l}\text { R.F } \\
\text { (gms) }\end{array}$ & $\begin{array}{l}\text { S.F } \\
\text { (gms) }\end{array}$ & $\begin{array}{l}\text { Epoxy } \\
\text { (gms) }\end{array}$ & $\begin{array}{l}\text { A. Ratio } \\
\text { of R.F }\end{array}$ & $\begin{array}{l}\text { A. Ratio } \\
\text { of S.F }\end{array}$ & $\begin{array}{l}\text { Chemical } \\
\text { treatment }\end{array}$ & \\
\hline 1 & 85 & 85 & 50 & 10 & 10 & Yes & 18368.894590 \\
\hline 2 & 85 & 85 & 50 & 15 & 15 & No & 17348.400450 \\
\hline 3 & 85 & 90 & 55 & 10 & 10 & No & 18643.057200 \\
\hline 4 & 85 & 90 & 55 & 15 & 15 & Yes & 16879.524760 \\
\hline 5 & 90 & 85 & 55 & 10 & 15 & Yes & 18292.037290 \\
\hline 6 & 90 & 85 & 55 & 15 & 10 & No & 18368.894595 \\
\hline 7 & 90 & 90 & 50 & 10 & 15 & No & 18102.678730 \\
\hline 8 & 90 & 90 & 50 & 15 & 10 & Yes & 18174.514750 \\
\hline
\end{tabular}

Table 5. Factors and levels factors and mean

\begin{tabular}{lllr}
\hline Factor & Level & Total & Mean \\
\hline A & 1 & $71239.877 / 4$ & 17809.96925 \\
& 2 & $72938.12536 / 4$ & 18234.53134 \\
B & 1 & $72378.22692 / 4$ & 18094.55673 \\
& 2 & $71799.77544 / 4$ & 17949.94386 \\
C & 1 & $71994.48313 / 4$ & 17998.62078 \\
& 2 & $72183.51355 / 4$ & 18045.87839 \\
D & 1 & $73406.66722 / 4$ & 18351.66681 \\
& 2 & 70771.335000 & 17682.83366 \\
E & 1 & $73555.36054 / 4$ & 18388.84014 \\
& 2 & $70622.64123 / 4$ & 17655.66031 \\
F & 1 & $71714.97139 / 4$ & 17928.74285 \\
& 2 & $72463.03097 / 4$ & 18115.75774 \\
G & 1 & 761.0000000 & 18022.25023 \\
\hline
\end{tabular}

Table 6. Intial ANOVA

\begin{tabular}{llrrr}
\hline Factor & DOF & \multicolumn{1}{c}{ S } & V & F \\
\hline A & 1 & 360505.9400 & 360505.9400 & 5.2934 \\
B & 1 & 41825.7640 & 41825.7640 & 0.6141 \\
C & 1 & 4466.5686 & 4466.5686 & 0.0655 \\
D & 1 & 868122.2300 & 868122.2300 & 12.7468 \\
E & 1 & 1075105.3000 & 1075105.3000 & 15.7860 \\
F & 1 & 69949.1290 & 69949.1290 & 1.0270 \\
Error & 1 & 68104.6440 & 68104.6440 & \\
Total & 7 & 2488079.6000 & 2488079.6000 & \\
\hline
\end{tabular}


Table 7. Final ANOVA

\begin{tabular}{llrrrrr}
\hline Factor & DOF & \multicolumn{1}{c}{ S } & V & S & \multicolumn{1}{c}{ P\% } & F \\
\hline A & 1 & 360505.9400 & 360505.9400 & 331938.13 & 13.3411 & 0.52060 \\
B & 1 & 41825.7640 & 41825.7640 & 650618.30 & 26.1494 & 6.04030 \\
C & 1 & 4466.5686 & 4466.5686 & 687977.50 & 27.6509 & 0.00645 \\
F & 1 & 69949.1290 & 69949.1290 & 622494.93 & 25.0190 & 10.10170 \\
Error & 3 & 2011332.2000 & 692444.0600 & 195051.06 & 7.8394 & \\
Total & 7 & 2488079.6000 & & & 100.0000 & \\
\hline
\end{tabular}

Where, S' = Pure sum of squares; P = Percentage of contribution

Sum of squares:

$\mathrm{S}_{\mathrm{T}}=18368.894^{2}+17348.40042+----++18174.514^{2}-$ $(144178.0018)^{2} / 8=2488079.62$

$\mathrm{S}_{\mathrm{A}}=\left(\mathrm{SUM} \text { OF } \mathrm{X}_{1}-\mathrm{SUM} \mathrm{OF} \mathrm{X}_{2}\right)^{2} / \mathrm{nr}$

Where:

$\mathrm{n}=$ No. of experiments in OA

$\mathrm{r}=$ No. of replications $($ Here, $\mathrm{r}=$ replications $=1$ )

$\mathrm{S}_{\mathrm{A}}=360505.9365$

$\mathrm{S}_{\mathrm{B}}=41825.76434$

$\mathrm{S}_{\mathrm{C}}=4466.5686$

$\mathrm{S}_{\mathrm{D}}=868122.2259$

$\mathrm{S}_{\mathrm{E}}=1075105.319$

$\mathrm{S}_{\mathrm{F}}=69949.12881$

$\mathrm{S}_{\mathrm{e}}=\mathrm{S}_{\mathrm{T}}-\mathrm{S}_{\mathrm{A}}-\mathrm{S}_{\mathrm{B}}-\mathrm{S}_{\mathrm{C}}-\mathrm{S}_{\mathrm{D}}-\mathrm{S}_{\mathrm{E}}-\mathrm{S}_{\mathrm{F}}=68104.64375$

Note:

DOF $($ TOTAL $)=($ No of trials -1$)=8-1=7$

DOF $($ Factor $)=($ No of levels -1$)=2-1=1$

DOF $($ Error $)=$ DOF $($ Total $)-$ DOF $($ all factors $)=7-6=$ 1

$\mathrm{V}$ - Variance $=\mathrm{S} / \mathrm{DOF}$

F- Statistic $(\mathrm{F})=\mathrm{V}($ Factor $) / \mathrm{V}$ (Error)

\subsection{Hardness Test}

Hardness of the three separate specimens and three reinforced composite material is determined by using Brinell Hardness Testing Machine. The specimen size used here is a circular rod of length of $65 \mathrm{~mm}$ and the diameter of $35 \mathrm{~mm}$. The specifications of the machine are ball intender of diameter $20 \mathrm{~mm}$ and the maximum load of $4000 \mathrm{~N}$. The formula used to determine the $\mathrm{BHN}$ of the specimen is given below and results are shown in Table 8.

$$
\mathrm{BHN}=\mathrm{P} / \mathrm{A}
$$

Where:

$\mathrm{P}=$ Load applied to the specimen

$\mathrm{A}=$ Area of the indendation
$\mathrm{P}=2500 \mathrm{~N}$

Area of the indendation (A):

$=\Pi \mathrm{D} / 2 *\left(\left(\mathrm{D}-\left(\mathrm{D}^{2}-\mathrm{d}^{2}\right)\right)^{0.5}\right.$

Where:

$\mathrm{D}=$ Diameter of the ball intender

$\mathrm{d}=$ Diameter of the indendation

Area of the indendation (A):

$=(\Pi * 20) / 2 *\left(\left(20-\left(20^{2}-7.4^{2}\right)\right)^{0.5}\right.$

$\mathrm{A}=29.2768 \mathrm{~mm}^{2}$

$\mathrm{BHN}=\mathrm{P} / \mathrm{A}$

\subsection{Pooling Rules Applied In Taguchi Designed Experiments}

To obtain a better estimate of the relative importance of each of the significant factor, non-significant factors are removed especially when more factors are involved. This is known as pooling.

If the F-statistics for any factor is less than one, then pool the 'SS' of that factor into the error term.

If the number of factors is not approximately one-half or less the number of columns in the table, pool the factors with the smallest F-Statistic until the no of factors remaining is approximately one-half of the no of columns.

\subsection{Interpretation of ANOVA}

- Factors A, B, C and F: Significant

- Factor A contributes maximum level of variation

- To decrease the youngs modulus of hybrid composite, level 2 of factors A and B and level 1 of factors $\mathrm{C}$ and $\mathrm{F}$ are selected.

\subsection{Scanning Electron Microscopy}

A Scanning Electron Microscopy (SEM) machine Model Hitachi S-3000N was used to study the effect of the microstructure of composites specimens with moisture and without moisture. 
Table 8. Table material comparison for hardness test

\begin{tabular}{ll}
\hline Material & BHN \\
\hline Banana & 323.0 \\
Sisal & 442.5 \\
Roselle & 767.0 \\
Roselle and Sisal (hybrid) reinforced composites & 338.2 \\
Banana and Roselle (hybrid) reinforced composites & 409.5 \\
Sisal and banana (hybrid) reinforced composites & 522.0 \\
\hline
\end{tabular}

\section{RESULTS AND DISCUSSION}

The hybrid composites showed comparatively better performance, the micrographs taken for the fractured sisal, banana, roselle and hybrid composites. Sisal and banana (hybrid) and Roselle and banana (hybrid) fiber composites, on tensile loading condition, showed a brittle like failure (less in \% of elongation, Fig. 8 and 9). Elliptical cracks and their fast propagation could be observed. Less fiber pull out is observed and this could be reason for the reduction in the tensile strength. The nature is justified, where more percentage elongation could be observed for the Sisal and Roselle (hybrid) (high in \% of elongation) fiber composites which exhibit ductile nature of fracture due to the presence of sisal fibers.

From the hardness test it is evident decreased fiber pull-out/Push-out by increasing fiber-matrix adhesion and decreased void formations around the fibers. Voids around the fibers and fiber pull out of the composites would have increased energy dissipation while fracture of composites, which has a positive hardness of composites. The moisture attacked the fiber-matrix interface, causing de-bonding of the fiber and the matrix. The failures of the composite materials were due to voids and the porosity. The fiber pullouts were identified from the fracture surface of the hardness tested composite specimens. Hardness number of Roselle and Sisal (hybrid) reinforced composites were 338.2, 409.5, for Banana and Roselle (hybrid) reinforced composites and 522.0 for Sisal and Banana (hybrid) reinforced composites which indicates Banana and Sisal (hybrid) has positive hardness compared to other two hybrid materials as said above.

The hybrid composites showed comparatively better performance, the micrographs taken for the fractured sisal, banana, roselle and hybrid composites. Sisal fiber composites, on tensile loading condition, showed a brittle like failure (Fig. 1).

Figure 2 shows that fibers are well anchored in the matrix and a very small amount of particulate are pulled out. The fractured surfaces are smooth and clear. This is observed due to the brittle nature of the bio epoxy matrix. It can be concluded that the fracture mainly happens in the matrix due to little void formation in the mid of the hybrid specimen and moisture presence in the material.

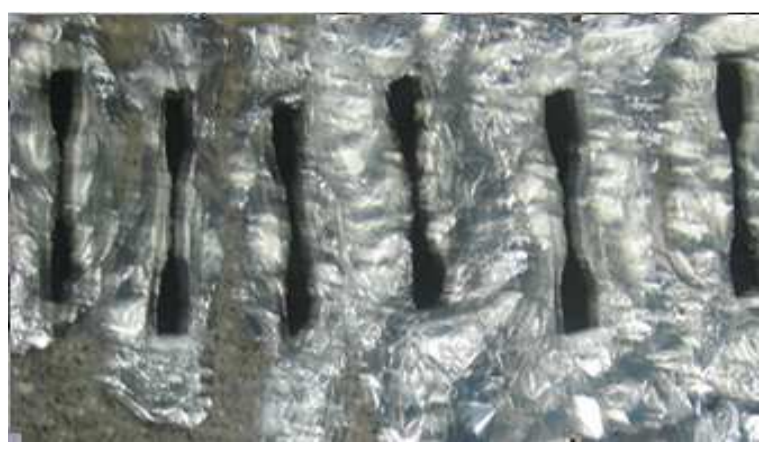

Fig. 1. Specimens for tensile test

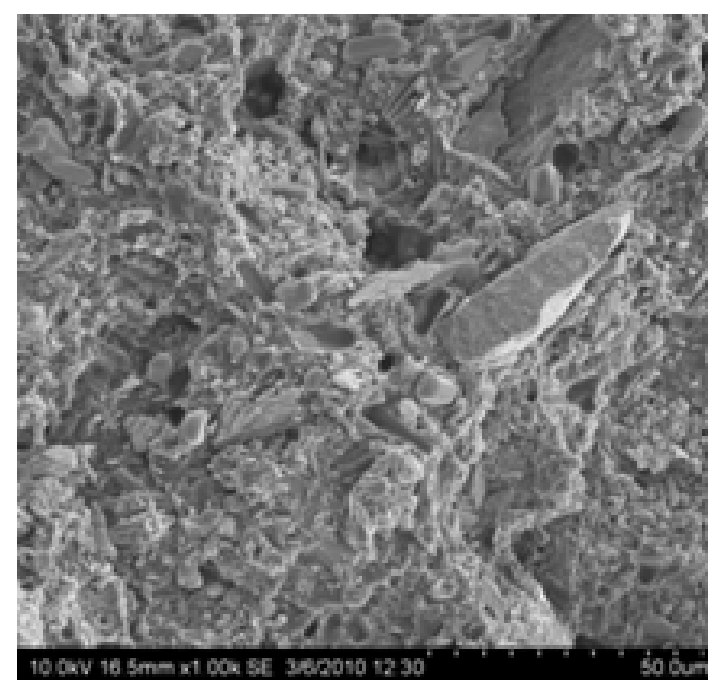

Fig. 2. SEM of Sisal and banana (hybrid) with Moisture

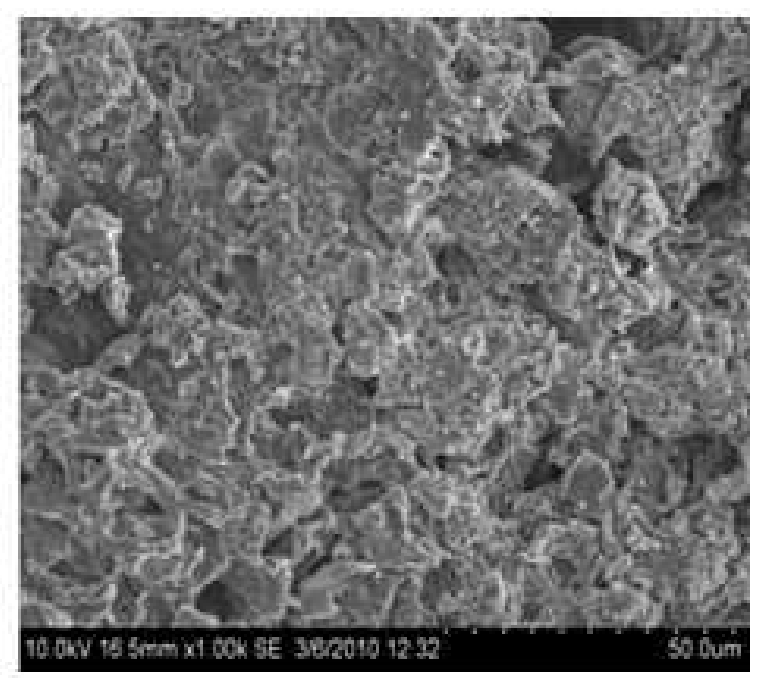

Fig. 3. SEM of Roselle and banana (hybrid) with Moisture 
Figure 3 shows An increase of the tensile strength and modulus occurred for the composites in moisture absorption conditions. It is also important to note that the effect of moisture absorption on the mechanical properties of the composites depends strongly on the temperature, fiber content and time of exposure.

Figure 4 shows fibre exposing out in certain spot, when axial tensile load is applied on the specimen, due to less bonding energy between sisal/roselle and the matrix. It pushes the particulate out while loading, while it can be improved when treating with alkali solution.

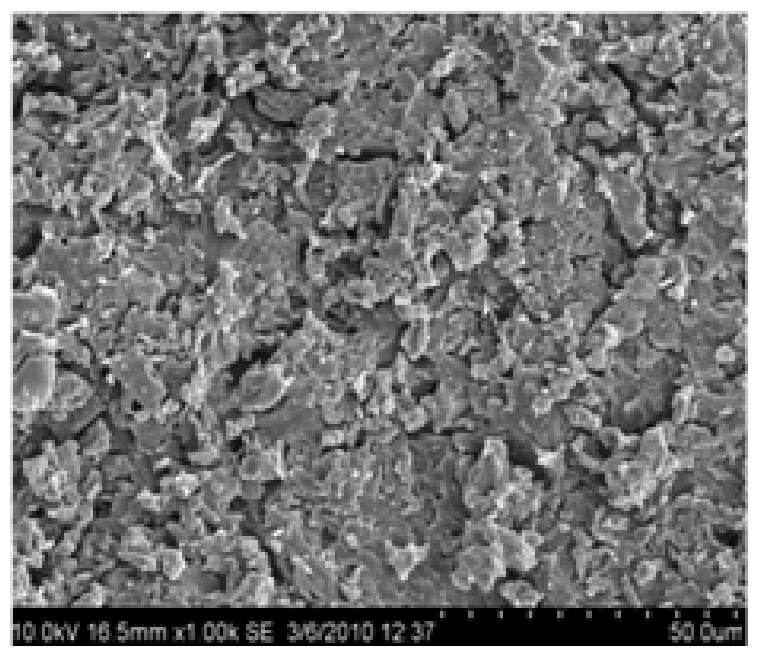

Fig. 4. SEM of Roselle and sisal (hybrid) with Moisture

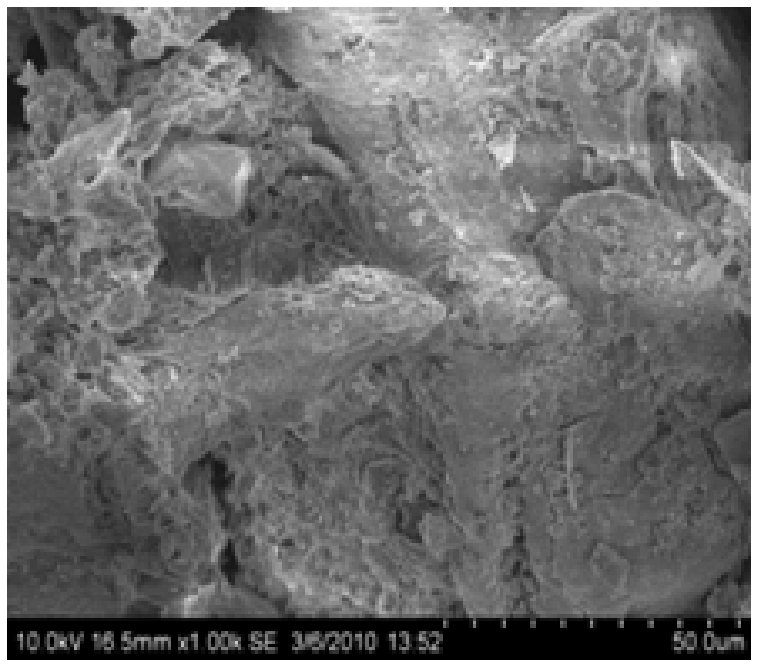

Fig. 5. SEM of Sisal and banana (hybrid) without Moisture

Science Publications
Figure 5 and 6 shows the presence of little cavities between material means at the interfacial bonding between the filler and matrix polymer is poor and weak. as the filler content increases, the poorly bonded interfaces and brittleness of the filler affect the tensile property(decreased strength and increased modulus). Improved interfacial bonding leads to improved tensile property due to proper mixing ratio of banana and roselle and also moisture condition. it improves better surface integrity.

Figure 7 shows fiber or particle pull out from the matrix in the presence of a tensile load is an indicator of lack of adhesion between fiber and matrix and increases surface roughness of fracture surface. These observations were also confirmed by tensile test results.

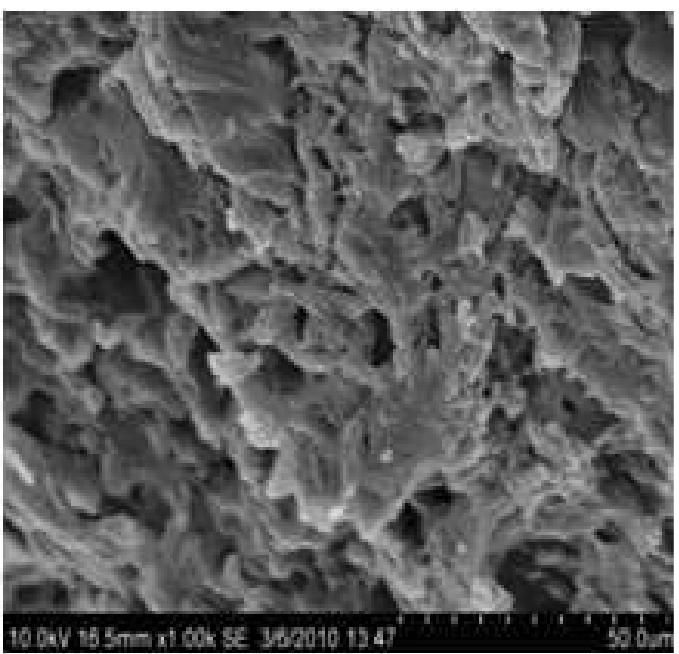

Fig. 6. SEM of Roselle and sisal (hybrid) without Moisture

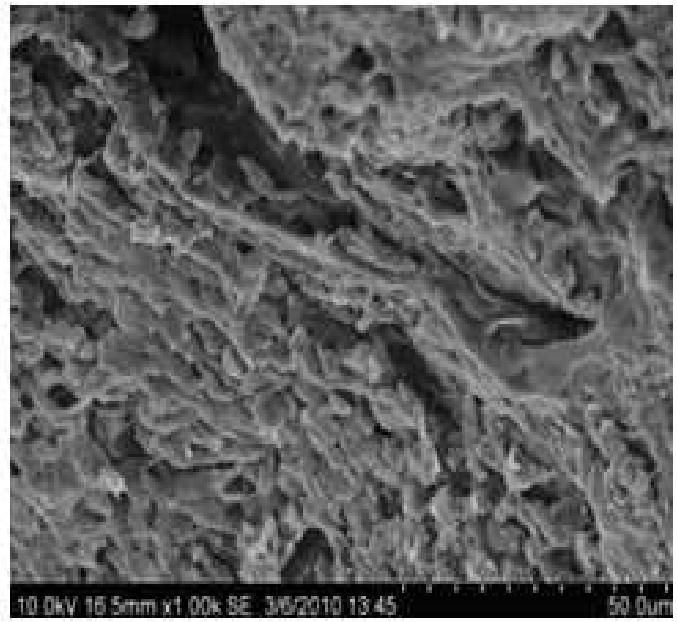

Fig. 7. SEM of Roselle and banana (hybrid) without Moisture 


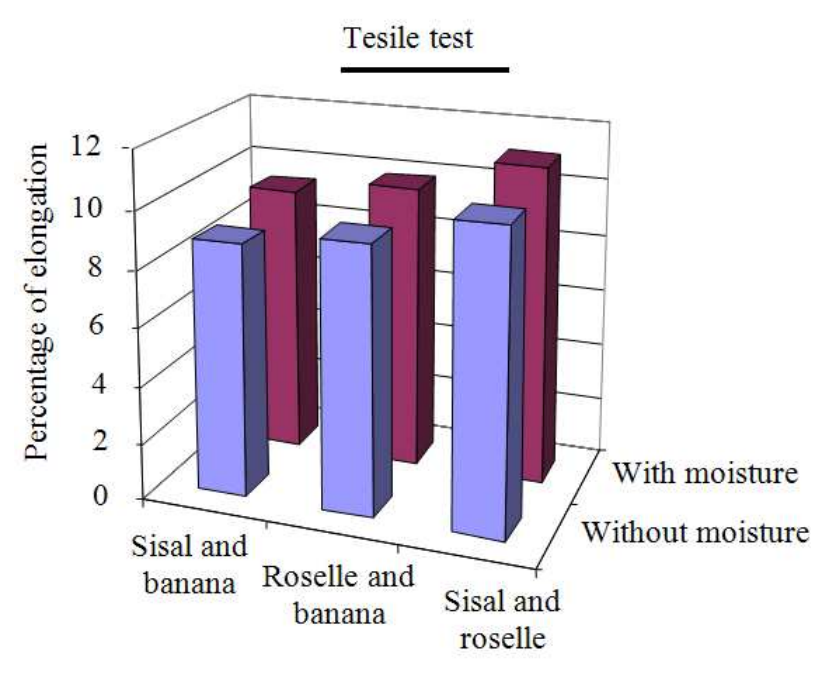

Fig. 8. Comparison of $\%$ of elongation

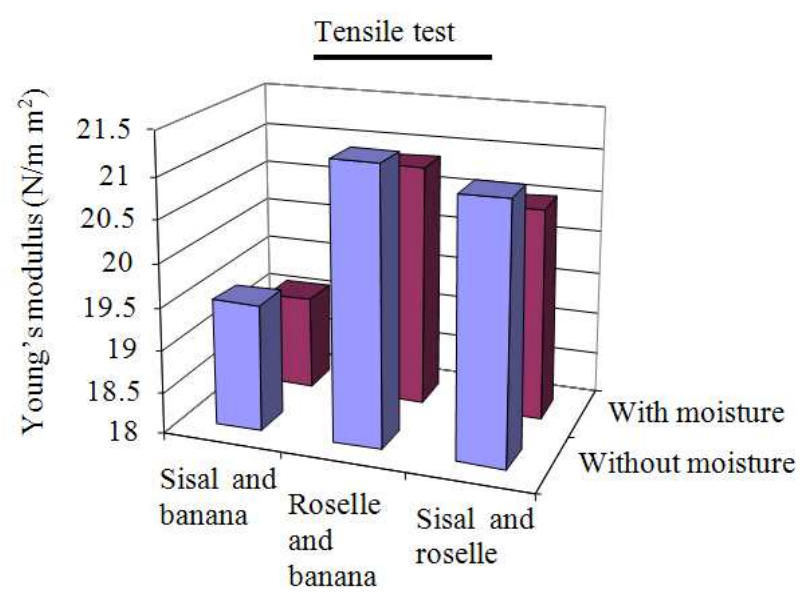

Fig. 9. Comparison of young's modulus

\subsection{Applications}

In the latest years industry is attempting to decrease the dependence on petroleum based fuels and products due to the increased environmental consciousness (Abrao et al., 2006). This is leading to the need to investigate environmentally friendly, sustainable materials to replace existing ones. The tremendous increase of production and use of plastics in every sector of our life lead to huge plastic wastes. Disposal problems, as well as strong regulations and criteria for cleaner and safer environment, have directed great part of the scientific research toward eco composite materials. Among the different types of eco-composites those which contain Natural Fibers (NF) and natural polymers have a key role. Since few years polymeric biodegradable matrices have appeared as commercial products, however their high price represents the main restriction to wide usage. Currently the most viable way toward eco friendly composites is the use of natural fibers as reinforcement (Blazewicz et al., 1997).

The hybrid composite material finds a lots of application. This material can be used in the automobile sector as replacement of plastic fibers which is already existing. The plastic fibre, which has a high carbon composition causes a problem for environment and moreover it is not a degradable one. Therefore these plastic fibers are not eco friendly (Joseph et al., 1999). In order to over come this problem the hybrid composite material used in this project can be replaced with plastic fibers (Abrao et al., 2006). This hybrid composite material has less carbon composition and it is a degradable one. In this project a rear view mirror, visor in two wheeler, billion seat cover, indicator cover, cover L-side, writing pen, name plate has been fabricated and it can be replaced with the existing above said fabricated with plastic fibers. While comparing both (Hybrid) composite materials has greater impact strength than the plastic fibre. The properties of natural fibers depend mainly on the nature of the plant, locality in which it is grown, age of the plant and the extraction method used. Roselle/Banana/Sisal fibers are abundantly found in the south India region, especially in Tamil nadu. Traditionally, these fibrous materials are being used by the local people for making low cost articles such as socks, boots, mats, ropes, bags. There is no literature available on the application of Roselle/Banana/Sisal hybrid fibers as reinforcing material in the polymer composites. Keeping in view the easy availability of these fibers, The automobile parts were fabricated using sisal and roselle fibers hybrid composites by hand lay up technique as shown in Fig. 10-14.

Elliptical cracks and their fast propagation could be observed. Less fibre pull out is observed and this could be reason for the reduction in the tensile strength. The tensile fracture micrograph for the fiber based composites. Plastic deformation and more fiber pull out could be observed. This nature is justified, where more percentage elongation could be observed for the hybrid fibre composites. Hybrid fibre composites exhibit partial brittle nature of fracture due to the presence of sisal fibers. 


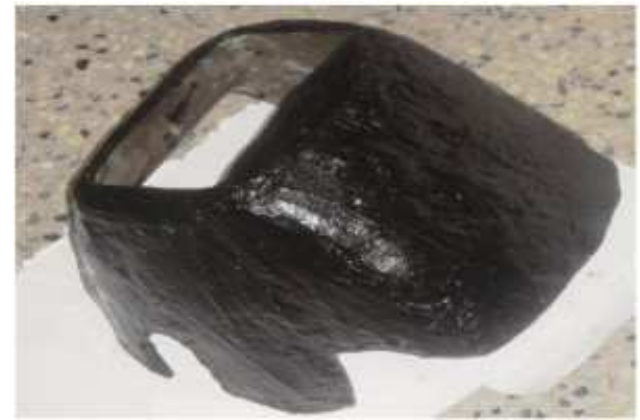

Fig. 10. Visor in two wheeler

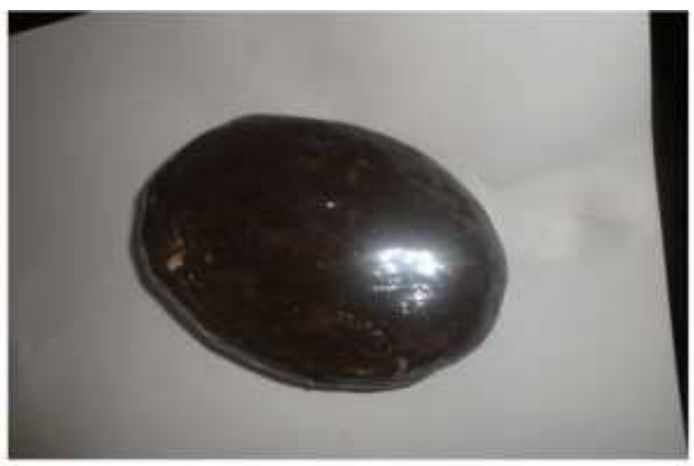

Fig. 11. Indicator cover

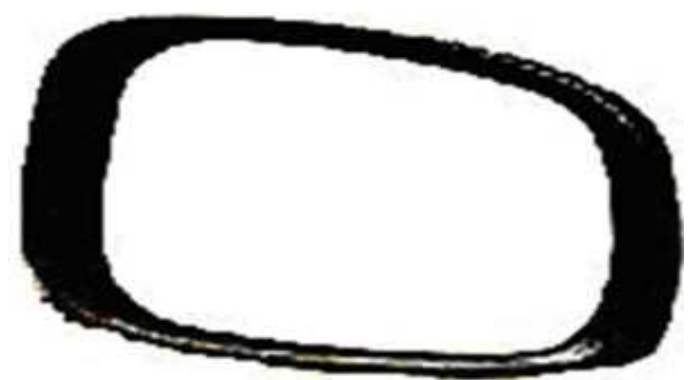

(a)

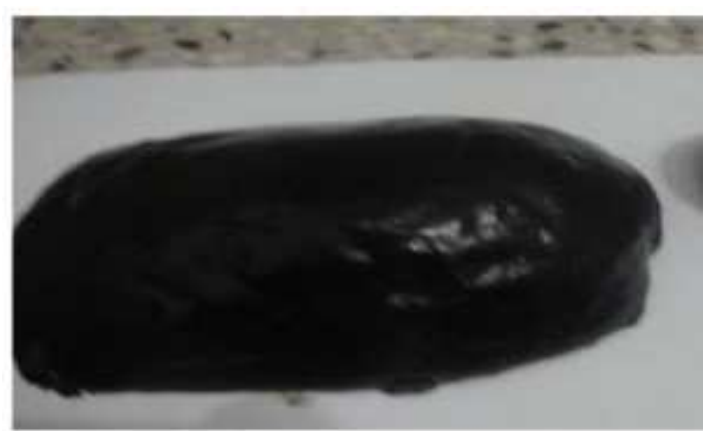

(b)

Fig. 12. (a) Rear view mirror (b) Rear view mirror

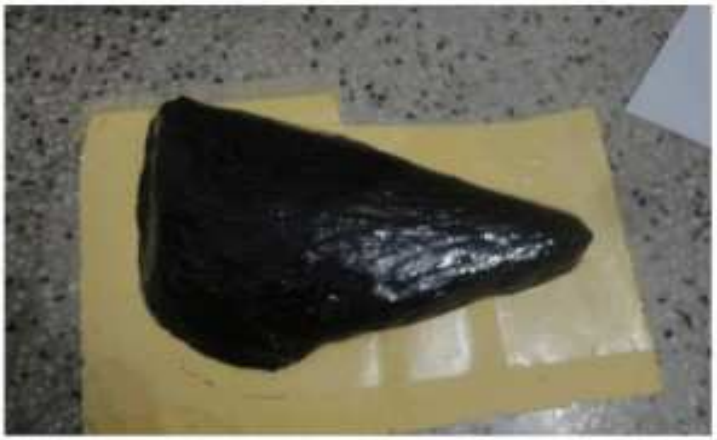

Fig. 13. Cover 1-side of two wheelers

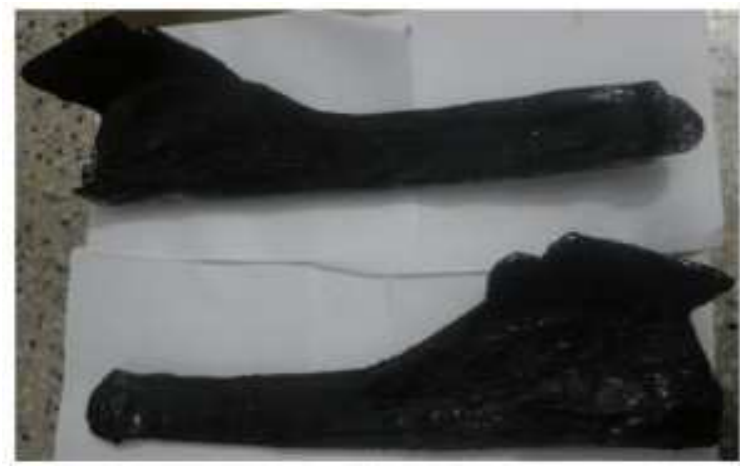

Fig. 14. Billian seat cover in two wheeler

\subsection{NF Composites, State-of-the-ART}

In the past two decades, growing interest for NF composites has resulted in extensive research. The driving forces are (i) cost reduction, (ii) weight reduction and (iii) marketing (application of renewable materials). Technical requirements were of less importance; hence application remained limited to non-structural parts for a long time. The reason for this is the traditional shortcomings of NF composites: The low impact resistance and moist degradation (Abrao et al., 2006). Recent research however showed that significant improvements of these properties are possible. Knowing that natural fibers are cheap and have a better stiffness per weight than glass, which results in lighter components, the grown interest in natural fibers is clear. Secondly, the environmental impact is smaller since the natural fibre can be thermally recycled and fibers come from a renewable resource. Their moderate mechanical properties restrain the fibers from using them in hightech applications, but for many reasons they can compete with glass fibers (Blazewicz et al., 1997).

Advantages and disadvantages determine the choice: 


\section{Advantages:}

+ Low specific weight, which results in a higher specific strength and stiffness than glass.

This is a benefit especially in parts designed for bending stiffness.

+ It is a renewable resource, the production requires little energy, $\mathrm{CO}_{2}$ is used while oxygen is given back to the environment.

+ Producible with low investment at low cost, which makes the material an interesting

product for low-wage countries.

+ Friendly processing, no wear of tooling, no skin irritation

+ Thermal recycling is possible, where glass causes problems in combustion furnaces.

+ Good thermal and acoustic insulating properties

\section{Disadvantages:}

- Lower strength properties, particularly its impact strength

- Variable quality, depending on unpredictable influences such as weather.

- Moisture absorption, which causes swelling of the fibers

- Restricted maximum processing temperature.

- Lower durability, fibre treatments can improve this considerably.

- Poor fire resistance

- Price can fluctuate by harvest results or agricultural politics.

\section{CONCLUSION}

After determining the material properties of natural fiber reinforced epoxy composite using six different tool materials and geometrics by using tensile test and hardness test can be drawn.

The hybrid composites showed comparatively better performance, the micrographs taken for the fractured sisal, banana, Roselle and hybrid composites. Sisal fiber composites, on tensile loading condition, showed a brittle like failure. Elliptical cracks and their fast propagation could be observed. Less fiber pull out is observed and this could be reason for the reduction in the tensile strength. The tensile fracture micrograph for the fiber based composites. Plastic deformation and more fiber pull out could be observed. This nature is justified, where more percentage elongation could be observed for the hybrid fiber composites. Hybrid fiber composites exhibit partial brittle nature of fracture due to the presence of sisal fibers. Finally this paper concluded that one of the best materials is sisal and Roselle (hybrid) can be used for make the variety of products in automobile accessories.

This project suggests that various car parts can be manufactured using hybrid reinforced composite material such as dash board, car roof, door handle, car door panels and the like.

This project has an application in the manufacture of name plate and also in pen.

Hybrid composite material has a very good insulating property. Hence it can be used as a circuit boards and switches. This project also finds its application computers by manufacturing cabinet of computer, frames of monitor and the like. Furniture can also be manufactured using this composite material.

All these studies show the excellent capability of biocomposites to be processed to structural parts. The weight-related properties also allow to aim at applications which are today dominated by glass fibre reinforced plastics. Nevertheless, there a restrictions with respect to extreme environmental conditions. An essential branch of applications is to be seen e.g. in covering elements with structural tasks in automobile and railway design, in furniture industry and in the field of leisure industry.

\section{REFERENCES}

Abrao, A.M., P.E. Faria, J.C. Campos Rubio and P. Reis et al., 2006. Drilling of fiber reinforced plastics: A review. J. Mater. Proc. Technol., 186: 1-7. DOI: 10.1016/j.jmatprotec.2006.11.146

Blazewicz, S., J. Chlopeka, A. Litak, C. Wajlera and E. Staszków et al., 1997. Experimental study of mechanical properties of composite carbon screws. Biomaterials, 18: 437-439. DOI: 10.1016/S01429612(96)00067-1

Boeree, N.R., J. Dove, J.J. Copper, J. Knowles and G.W. Hastings, 1993. Biomaterials, 14: 793-796. DOI: 10.1016/0142-9612(93)90046-5

Chandramohan, D. and K. Marimuthu, 2010a. Contribution of biomaterials to orthopaedics as bone implants-a review. Proc. Int. J. Mater. Sci., 5: 445-463. 
Chandramohan, D. and K. Marimuthu, 2010b. Thrust force, torque in drilling the natural fiber reinforced polymer composite materials and evaluate delamination factor for bone graft substitutes-a work of fiction approach. Proc. Int. J. Eng. Sci. Technol., 2: 6437-6451.

Chandramohan, D. and K. Marimuthu, 1994. Natural fiber bone plates as substitutes for orthopaedic alloy plates. Proc. Int. J. Biotechnol. Bioinform. Bioeng.,

Chandramohan, D. and K. Marimuthu, 2000. Deflection test on natural fibers and its application in bone grafting substitutes. Proc. Int. J. Eng. Sci. Technol.

Chandramohan, D., K. Marimuthu, S. Rajesh and M.M. Ravikumar, 2010a. Application of advanced design and development techniques in orthopaedics. Proc. Int. J. Applied Eng. Res., 5: 1653-1666.
Chandramohan, D., K. Marimuthu, S. Rajesh and M. Ravikumar, 2010b. Applications of CT/CAD/RPT in the futuristic development of orthopaedics and fabrication of plate and screw material from natural fiber particle reinforced composites for humerus bone fixation-a future drift. Malaysian J. Educ. Technol., 10: 73-81.

Clemons, C.M. and D.F. Caulfield, 1994. Natural fibers Sage. J. Reinforced Plastics Comp.

Joseph, K., R. Dias, T. Filho, B. James and S. Thomas et al., 1999. A review on sisal fiber reinforced polymer. Comp. Rev. Bras. Eng. Agric. Ambiental, 3: 367-379. 